\title{
Poesía carcelaria, repertorio poético y subjetividades en conflicto: el poemario Alde erantzira nabil de Ekhiñe Eizagirre ${ }^{1}$
}

\author{
Iratxe Retolaza Gutierrez \\ Universidad del País Vasco / Euskal Herriko Unibertsitatea UPV/EHU
}

Resumen: En el campo de la literatura vasca la poesía carcelaria ha alcanzado una considerable incidencia desde que el conocido poeta Joseba Sarrionandia fuera encarcelado, y publicara Kartzelako poemak [Poemas desde la cárcel] (Susa, 1992). Tras ese hito literario, se han publicado con regularidad poemarios carcelarios tanto en editoriales literarias como en plataformas alternativas; pero hasta el 2016, año en el que Ekhiñe Eizagirre presentó Alde erantzira nabil [Camino del revés] (Susa, 2016), no se publicó ningún poemario carcelario de autoría femenina. En este artículo se analiza el poemario de Ekhiñe Eizagirre, comparándolo con los símbolos e imaginarios construidos en poemarios carcelarios anteriores, para mostrar cómo ha renovado ese imaginario colectivo tanto desde una perspectiva feminista, como desde lo comunitario. Para ello, se analizan los discursos y posiciones genéricas de los sujetos encarcelados, y a su vez, se reflexiona sobre la posición de estos repertorios poéticos en el campo literario vasco.

Palavras clave: Poesía carcelaria, construcción de género, campo literario vasco, incidencia política

Abstract: Prison poetry has had a considerable impact in the Basque literary field ever sincethe well-known poet Joseba Sarrionandia published Kartzelako poemak [Poems from the jail] (Susa, 1992) during his imprisonment. Since that literary milestone, several prison poetry books have been published both by publishing companies and by alternative platforms.; However, it was not until 2016, when Ekhiñe Eizagirre published Alde erantzira nabil [I walk upside down], that the first prison poetry book by a female author was published. In this article, the poetry collection by Ekhiñe Eizagirre is analyzed through a comparison with the symbols and imagery from previous examples of prison poetry. The analysis shows how she innovated this 
collectively produced imagery from a feminist perspective and from within the community. To this end, this paper analyses the gender discourses and opinións of the imprisoned subjects, and reflects on the position of these poetic repertoires in the Basque literary field.

Keywords: Prison poetry, gender construction, Basque literary field, political

\section{Introducción}

This too I know - and wise it were

If each could know the same-

That every prison that men build

Is built with bricks of shame,

And bound with bars lest Christ should see

How men their brothers maim.

With bars they blur the gracious moon,

And blind the goodly sun:

And they do well to hide their Hell,

For in it things are done

That Son of God nor son of Man

Ever should look upon!

Oscar Wilde, The Ballad of Reading Gaol, 1897.

Las prisiones, como dispositivos disciplinarios, instauran el cautiverio de las personas condenadas, a la vez que regulan las subjetividades de esas personas encarceladas, a 193 se les niega la voz pública, o se les obstaculiza la comunicación con el exterior. Como declamó Oscar Wilde, toda prisión está construida con el objetivo de ocultar la violencia física y simbólica que se ejerce tras los muros, y para ello, la institución penitenciaria entorpece todo discurso testimonial de los sujetos encarcelados. Como gesto de resistencia o subsistencia, han sido muchas las personas encarceladas que han hecho uso de la palabra escrita para dar testimonio de su cautiverio, para intentar despojarse de esa posición 
subalterna. Como advierte Estibaliz de Miguel (2016), escuchar esas voces y esas experiencias silenciadas nos ayuda a comprender y aprender:

\footnotetext{
Siguiendo a Gayatri Spivak, se trata de romper con el silenciamiento que padecen determinados grupos sociales, un silenciamiento del que todos y todas de alguna manera somos cómplices, y empeñarnos en 'la labor de ir descifrando las palabras ajenas desde una institución académica' (2002: 213) o desde el lugar político que cada cual ocupe, podríamos añadir. (De Miguel 2016: 16)
}

Estos testimonios escritos, aun plasmándose muchas veces en géneros literarios (crónicas, narraciones, poesía, etcétera), habitualmente se han situado fuera del campo literario (Lourido 2012, 2015). Sin embargo, como expondré en este artículo, en la literatura vasca se han publicado con regularidad poemarios carcelarios tanto en editoriales literarias como en plataformas alternativas, y la poesía carcelaria ha obtenido una cierta posición de campo, gracias a la consolidación de ese repertorio poético. No obstante, hasta el 2016, año en el que Ekhiñe Eizagirre presentó Alde erantzira nabil [Camino del revés] (Susa, 2016), ${ }^{2}$ no se había publicado ningún poemario carcelario de autoría femenina.

Estibaliz de Miguel subraya que en el caso de las mujeres presas, el silenciamiento y el aislamiento es mayor, y por tanto, es necesario activar una escucha política que reconozca su capacidad de agencia: "Se trata no sólo de aliviar sus padecimientos sino también de crear cauces para que ellas puedan colaborar activamente en la descripción de la realidad, en la propuesta de alternativas al actual sistema punitivo y en el camino hacia una sociedad sin cárceles" (De Miguel 2016: 30). En ese contexto, en este artículo activaré esa escucha política, para comprender cómo ha contribuido este poemario a repensar el imaginario genérico que se había consolidado en los poemarios carcelarios anteriores.

\section{La institución penitenciaria y las experiencias carcelarias}

Antes de centrarme en dicho acontecimiento literario, esbozaré unas breves notas sobre los estudios antropológicos y sociológicos. Desde que Michel Foucault publicó su estudio sobre las instituciones penitenciarias, Surveiller et Punir: Naissance de la prison, en 1975, el interés por las experiencias carcelarias ha ido en aumento. En esta conocida obra, analiza la evolución de los sistemas penales occidentales durante la era moderna, y 
concretamente, en el cuarto capítulo trata con detenimiento los mecanismos disciplinarios y represivos de la institución penitenciaria. Como afirma Foucault (2012: 159), la prisión asume la función de aparato del Estado para transformar a los individuos, y para ello reproduce, acentuados, todos los mecanismos disciplinarios que aparecen en la sociedad. Entre ellos, la regulación de género. De hecho, en la actualidad las prisiones son uno de los lugares donde la segregación de género se instaura con mayor rigidez, y los roles de género están fuertemente marcados.

En consecuencia, en los estudios antropológicos y sociológicos feministas se han desarrollado múltiples investigaciones sobre esos mecanismos disciplinarios patriarcales, y sobre las experiencias carcelarias de mujeres presas (y sus formas específicas de resistencia). En las dos últimas décadas diversos trabajos (Bosworth 1999; Almeda 2002; Matthews 2003; Hernández Holgado 2011; Juliano 2011) han criticado la visión histórica foucaultiana, puesto que al describir la evolución de los sistemas de cautiverio, no atiende a las instituciones que históricamente mantuvieron cautivas a mujeres, ni a experiencias carcelarias propias de las presas (apud Ruiz Torrado 2017: 43-56). Gracias a todos esos trabajos, se han detectado las discriminaciones a las que se ven sometidas las mujeres por parte del sistema penal y penitenciario (dispersión territorial, actividades formativas feminizadas, régimen de visitas orientado al cuidado, etcétera). Concretamente, en esa línea teórica se han desarrollado en los últimos años varias aportaciones del grupo de investigación de Antropología Feminista (AFIT) de la UPV/EHU, dirigido por Mari Luz Esteban. Destaca entre los trabajos realizados, la tesis de María Ruiz Torrado (2017), que aborda las formas de resistencia de las presas en cárceles vascas; y entre las que se mencionan tanto la creatividad como la escritura (Ruiz Torrado 2017: 235-276).

Ese interés de la antropología feminista por aproximarse a las experiencias de mujeres presas, ha confluido con el proceso de resolución del conflicto político-armado del País Vasco. Desde que en 2010 ETA anunciara el alto el fuego definitivo ${ }^{3}$, se han desarrollado diferentes foros para elaborar una revisión del pasado y atender las consecuencias del conflicto. Como es conocido, en los Estudios de la Memoria o en los procesos de reconciliación, al analizar pasados bélicos o pasados en conflicto, se han desarrollado investigaciones y trabajos específicos tanto de cárceles de mujeres, como de las situaciones 
de violencia específica contra las mujeres (Hernández Holgado 2011; Grau Biosca 2014). Desde esa perspectiva feminista, en el País Vasco se han activado en los últimos años diferentes foros para realizar un análisis con perspectiva de género tanto del conflicto armado como del proceso de resolución. Se han generado espacios de debate dinamizados por movimientos sociales, como por ejemplo Euskal Herriko Bilgune Feminista, el movimiento feminista independentista ${ }^{4}$; o foros articulados en instituciones públicas, como por ejemplo Emagune (2014), en la UPV/EHU, que ha hecho públicas varias reflexiones sobre el proceso de pacificación desde una perspectiva de género. ${ }^{5} \mathrm{E}$ incluso, se han activado espacios de encuentro entre agentes académicos y militantes del movimiento feminista. Cabe destacar la aportación de las Jornadas de Metodología de Investigación Feminista organizadas por Hegoa (UPV/EHU) [Instituto de Desarrollo y Cooperación Internacional] y SIMReF [Seminario de Metodología en Investigación Feminista], que tanto en la edición de 2014 como en la edición de 2018 abordaron el tema de la violencia y los contextos políticos en conflicto desde una perspectiva metodológica feminista, y gracias a los que se socializaron las investigaciones e intervenciones feministas realizadas en otros procesos de resolución contemporáneos, como Colombia (Grau Biosca 2014).

Esas dinámicas han generado un interés y una necesidad de ahondar en esas realidades, y algunas investigadoras han dirigido sus tesis doctorales a analizar desde una perspectiva feminista experiencias carcelarias en el contexto del conflicto armado (entre ellas destacan las aportaciones de Olatz Dañobeitia, 2018). Considero que es concretamente ese humus sociopolítico y sociocultural el que alentó la propuesta poética de Ekhiñe Eizagirre, y el que favoreció la publicación de este primer poemario carcelario de autoría femenina.

Ekhiñe Eizagirre fue detenida y encarcelada en el Estado francés en mayo de 2013, acusada de ser miembro de ETA; y estando a la espera de juicio, escribió ese poemario en la cárcel de Fresnes (a las afueras de París). La juzgaron en 2017, y la condenaron a seis años de prisión por pertenencia a banda armada. En la actualidad está en libertad, tras haber cumplido íntegramente su condena. Cabe destacar que Ekhiñe Eizagirre antes de estar en busca y captura (desde 2010), era militante feminista en Euskal Herriko Bilgune Feminista. Tras su detención, retomó esa militancia feminista, y participó activamente desde la cárcel 
en el movimiento feminista (dentro de sus posibilidades), escribiendo textos de opinión o creando imágenes para chapas, carteles o trípticos de jornadas feministas ${ }^{6}$.

Para poder comprender el contexto en los que emergen los poemas de Eizagirre, a continuación reuniré las discriminaciones a las que fue sometida en su encarcelamiento en el Estado francés, partiendo de las reflexiones y consideraciones desarrolladas en los estudios antropológicos y sociológicos feministas:

La dispersión territorial: generalmente hay pocas cárceles específicas para mujeres, las presas están normalmente en módulos dentro de las cárceles para hombres. (Manzanos 2016: 42)

El enfoque resocializador de género:

La mayoría de programas educativos, formativos y laborales, así como la oferta cultural y recreativa, refuerzan su papel tradicional a través de actividades y cursos como tintorería, costura, maquillaje, cerámica o macramé, que parecieran más encaminadas a su feminización que a una teórica resocialización (De Miguel 2016: 20).

El enfoque moralizador, una doble condena:

Dicho de otro modo, históricamente las mujeres han sido penadas por conductas no castigadas en los hombres, tales como el adulterio, el concubinato, la separación, el divorcio o la prostitución (Yagüe 2006). Así las cosas, las penas impues tas a las mujeres tienen un carácter moralizador: son una mezcla entre castigo y pecado. La sanción sufrida por las mujeres va más allá de la infracción legal, pues también se le impone un castigo por haberse alejado de los roles que le impone la sociedad. (Martínez Pérez 2016: 56)

Sentimiento de desarraigo familiar: "En las cárceles de hombres las familias son sentidas como el apoyo y el sostén de los presos durante la condena. Sin embargo, en las cárceles de mujeres las familias son sentidas como aquello que se ha abandonado y causa de culpa permanente" (Sainz de Rozas 2016: 77-78).

La privación de la sexualidad: si en toda cárcel la sexualidad está regulada y vigilada, en el Estado francés se agrava la situación, porque no están permitidas las relaciones 
sexuales en los vis a vis (EMAGIN/EHBF 2017: 28). Evidentemente, el hostigamiento es mayor en el caso de las relaciones homoeróticas:

\footnotetext{
Por último no podemos obviar, otro de los exponentes más destacables del carácter heteropatriarcal de la cárcel como es las situaciones de discriminación que frecuentemente sufren las mujeres por el hecho de tener relaciones afectivas no heterosexuales a la hora de poder acceder a comunicaciones vis a vis e íntimas con sus compañeras sentimentales. (Manzanos 2016: 46)
}

Las presas de ETA, regímenes de cautiverio extremos: por el carácter del delito, a las presas de ETA se les aplica la legislación antiterrorista7, y por consiguiente, la experiencia carcelaria es más extrema: control mucho más severo (se les intervienen todas las comunicaciones, y se determina cuántas cosas y qué cosas pueden tener en la celda), constantes cacheos, mayor aislamiento, y cumplimiento íntegro de la condena (Martínez Pérez 2016: 62-64).

Como reivindica Angela Davis (2016: 103-104), es necesario concebir esas capas de violencia a las que son sometidas las mujeres presas, para poder comprender las complejidades de los procesos de represión política. En el caso que nos ocupa, comprender esas capas de violencia a la que ha sido sometida Ekhiñe Eizagirre, es crucial para comprender cómo ha articulado la resistencia poética y la agencia política.

\section{Literatura carcelaria, repertorios poéticos y campo literario}

En el ámbito de la teoría literaria todavía escasean los estudios exhaustivos sobre la literatura carcelaria, pero en las últimas décadas se han desarrollado importantes aproximaciones críticas. Comenzando por los primeros estudios sobre la literatura francesa (Brombert 1976), influidos por la repercusión de los estudios foucaultianos, hasta la obra pionera de Maria José de Queiroz (1981), que realiza una revisión histórica minuciosa de la literatura carcelaria, atendiendo a autores de diferentes épocas y sociedades. ${ }^{8}$ En estas aproximaciones críticas, han recibido especial atención los textos publicados por escritores consagrados $^{9}$ o por reconocidos militantes sociales y políticos. Es decir, se ha prestado atención a los sujetos encarcelados que ya dotaban de cierto capital simbólico (cultural o político), que avalaba bien el interés literario bien el interés testimonial de dichas obras. 
Según loan Davies (1990: 7), algunas culturas han mostrado más interés por la literatura carcelaria (como Francia, Rusia o Sudáfrica). Evidentemente, en las últimas décadas, los Estudios de la Memoria que se han centrado sobre todo en conflictos políticos, se han aproximado a la literatura carcelaria (como literatura testimonial). De esa manera, se ha extendido el interés por la literatura carcelaria: por ejemplo, en la literatura brasileña (Ovídio Poli Junior 2009), la literatura argentina (Amandine Guillard 2015), la literatura irlandesa (McCann 2012, 2015), etcétera. En algunas de estas aproximaciones literarias también se ha desarrollado una perspectiva de género, sobre todo en los contextos en que se han generado dinámicas sociales para analizar el conflicto desde una perspectiva feminista.

En la mayoría de estos trabajos se menciona la necesidad de definir y delimitar la literatura carcelaria, como un género literario que se expresa en diferentes tipologías textuales (cartas, crónicas, diarios, manifiestos, poesía, narrativa, etcétera). En estas aproximaciones críticas se enumeran las siguientes características de la literatura carcelaria. En lo que a la difusión se refiere, los escritos carcelarios no se suelen publicar en plataformas literarias de prestigio, muchas veces sufren la censura, y muchas otras, se publican en plataformas alternativas de movimientos sociales o políticos, por su carácter contestatario (Lourido 2012). No suelen compartir el mismo circuito que otras obras literarias. Maria José de Queiroz afirma que:

Não convém, isso posto, abordar-Ihes os escritos do cárcere com o mesmo interesse es tético com que nos aproximamos de suas obras. Tolhido na sua liberdade, colido na rede do poder, o escritor alienase ao mando que o subjuga. Estranho à própria inteligência, destituído da identidade pessoal, que o situa no espaço e no sistema: de infrator, inicialmente, transmuda-se em delinqüente; de detento ou subversivo, em dissidente ou revolucionário [...]. Por isso, as páginas escritas nas celas estreitas e mal iluminadas, à míngua de todo estímulo intelectual, nem sempre instruem acerca de autores, enquanto artistas e criadores. Instruem-nos, sim, na disciplina monstruosa cujo exercício se funda nas prerrogativas do mando. Seu interesse? O protesto, a denuncia, o desabafo [...] Ao réu, ou vítima, destituído de direitos, não se concede palavra. E, proferida, continuará inédita. Sem qualquer ressonância.

A literatura do cárcere - memórias, cartas, confissões, libelos, denuncias, manifestos dificilmente logra, por essas e mais graves razões de sigilo, censura ou segurança nacional, divulgação imediata. Se publicada, a distância que a separa do tempo e lugar de origem age em detrimento da 
sua eficácia. Destituído do vigor da atualidade, o testemunho político adquire, compensadoramente, importancia histórica, arqueológica às vezes, de nefasta memória. (Queiroz 1981: 20)

En lo que a la posición enunciativa se refiere, el encarcelamiento del escritor / de la escritora marca fuertemente el pacto de lectura. Como afirma loan Davies (1990: 9), la persona presa es una otra marginalizada, una subalterna que según el sistema penal y penitenciario no tiene capacidad o legitimidad para representarse a sí misma. En opinión de Davies (ibídem: 9), es una tradición cultural a tener en cuenta y a analizar: porque los sujetos encarcelados lejos de admitir silenciosamente su destino, han luchado por erigirse en sujetos carcelarios, alzando la voz, para mediante la palabra, crear espacios de resistencia. A su vez, la circunstancia vital del escritor / la escritora condiciona la experiencia lectora, porque nos remite a un sujeto privado de libertad, con quien podemos compartir o no compartir experiencia, pero cuya credibilidad biográfica no cuestionamos, y cuyas palabras, por el mero hecho de haberse enunciado en cautiverio y haber transcendido los muros, portan una carga tanto testimonial como performativa. Toda literatura carcelaria, toda palabra carcelaria, nos interpela directamente, generándonos preguntas sobre la libertad, sobre nuestra posición social y espacial, sobre el sistema penitenciario, sobre la subalternidad.

En lo que a las formas discursivas se refiere, en todas estas aproximaciones críticas se subrayan ciertos mecanismos que son constantes en obras escritas en prisión. La literatura carcelaria es principalmente autorreflexiva y autoafirmativa (ibídem: 235). La experiencia carcelaria es tan fuerte que al sujeto carcelario le es imposible tratar la experiencia con objetividad y distancia:

O prisioneiro, dominado pelo sentimento de impotência, desligado do passado e do futuro, obrigado a assumir, no presente, uma nova identidade, nem sempre consegue recuperar o grau de objetividade (ou de lucidez) indispensável para transformar dúvidas e contra dições em verdade - a sua verdade. O que vale dizer, a sua versão, equilibrada e real, da experiência vivida. Daí, a falência de muitos. E, sobreleva notar, mesmo o escritor de ofício, inibido pelas condições que o exoneram do papel de espectador, transformando-o em ator, sofre a influência desmoralizadora da prisão. À mercê da máquina carcerária, num diferente aglomerado humano e social, sujeita-se, ao expressar-se, a bem distintas exigências [...]. Acreditamos que a maior dificultade do artista, ou criador, em atingir um conhecimento equilibrado do que é e de quem é, resulte na situação anômala em que se encontra, 
sendo ele próprio parte integrante do todo que determina a significação dos fenômenos e dos mecanismos de comportamento dos seres que com ele convivem (Queiroz 1981: 21).

Asimismo, la escritura carcelaria tiende a la siguiente dualidad: la posición autorial es tanto solitaria como grupal. Según Queiroz (ibídem: 54), aunque el grupo no esté organizado, la pertenencia a una comunidad (los sujetos encarcelados, los sujetos privados de libertad) está muy presente en la escritura carcelaria. De esa manera, el bien personal se identifica con el bien común: el ansia de libertad identifica a todo ser humano.

Las topoi propios de la producción carcelaria en general son: las comunicaciones codificadas con las demás personas detenidas; la domesticación de los insectos; las tentativas de escribir con medios improvisados; las inscripciones murales, etcétera (Brombert 1975). También son recurrentes las temáticas existenciales más generalistas: la pérdida del tiempo - se representa un interminable aquí y ahora - (Queiroz 1980: 21), y la predominancia de lo espacial (Davies 1990: 60); la contemplación de la muerte (ibídem: 68); el poder, la dominación y la transcendencia (Gelfand 1983: 20). En ese afán de transcender la prisión, el sujeto encarcelado se despoja de su cuerpo (separando lo espiritual de lo material), y se refugia en la mente, en el alma. No es así en el caso de las mujeres encarceladas: su corporalidad es enfatizada (Gelfand 1983: 21). Muchas de las mujeres encarceladas se definen como doblemente oprimidas: en primer lugar como mujeres, y en segundo lugar como prisioneras, en ambos casos, presas de un sistema que regula y controla sus cuerpos. En el caso de las presas, por tanto, la escritura siempre es un acto subversivo (Gelfand 1983: 35), porque socavan las expectativas culturales que les ha impuesto la sociedad que las tiene encarcelada.

\section{El campo literario vasco y el repertorio poético-carcelario}

En el ámbito de la literatura vasca la poesía de temática carcelaria ha sido una constante desde el siglo XVI; pero durante siglos se publicaron básicamente poemas o versos integrados en obras más extensas. En 1992, un acontecimiento posicionó en el centro del campo literario vasco la poesía escrita en la cárcel: el conocido poeta Joseba Sarrionandia publicó Gartzelako poemak [Poemas carcelarios] (Susa, 1992). ${ }^{10}$ La aportación de Joseba Sarrionandia es fundamental para entender esta posición de campo. La andadura poética de 
Sarrionandia comenzó en la década de los 70 en el grupo de poesía Pott banda [Banda fracaso]. En este grupo literario se reunieron escritores y artistas tan reconocidos o conocidos actualmente como Bernardo Atxaga, Jimu Iturralde, Jon Juaristi o Ruper Ordorika. Por lo tanto, Sarrionandia era un poeta de renombre cuando lo detuvieron: fue encarcelado en 1980 acusado de ser miembro de ETA, y se escapó de la cárcel en 1985, escondido en un bafle.

Tras ese hito literario se han publicado con regularidad obras de temática carcelaria escritas tanto por presos de ETA como por presos de movimientos políticos y sociales: poemas $^{11}$, narraciones ${ }^{12}$, novelas ${ }^{13}$, crónicas $^{14}$, cómics $^{15}$, e incluso una obra teatral ${ }^{16}$. A partir de 2002, la mayoría de esos testimonios se han publicado en Ataramiñe [Sacar el dolor], una plataforma editorial creada para publicar las obras literario-artísticas de los miembros del Colectivo de Presos Políticos Vascos. Esta plataforma, además de obras de autoría individual, promueve una publicación colectiva anual.

En esa producción carcelaria ha destacado el género poético, tanto cuantitativamente, como cualitativamente, por ser el género que más se ha difundido en editoriales literarias (Elkar, Maiatz, Susa). De hecho, muchos de esos poemarios carcelarios se han publicado en la editorial Susa ${ }^{17}$, una de las editoriales más prestigiosas en lo que al género poético se refiere. Recuérdese que fue en esa misma editorial donde se divulgó el poemario de Joseba Sarrionandia, que se publicó con el aval de sus compañeros del grupo poético Pott banda, Ruper Ordorika y Jimu Iturralde, que escribieron un prólogo y un epílogo respectivamente (Rodriguez 2014: 93-94). Aunque destaca el repertorio poético, la editorial Susa ha publicado literatura carcelaria en otros géneros literarios, e incluso publicó un ensayo sobre la literatura carcelaria vasca ${ }^{18}$, y a su vez, algunos miembros destacados de la editorial han organizado recitales poéticos de literatura carcelaria, o han ofrecido charlas sobre literatura carcelaria, generalmente en círculos y programaciones literarias.

En la poesía carcelaria vasca se aprecian todas las características discursivas mencionadas (véase apartado 3). He aquí unos poemas que ejemplifican algunas de esas características. En el poema "II. Galdera" [II Pregunta] ${ }^{19}$ de Joseba Sarrionandia (1992), se aprecian la domesticación del insecto y el paso del tiempo. En otro poema, "Lau bost sei horma" [Cuatro cinco seis muros] ${ }^{20}$, Sarrionandia (1992) alude al poder, la dominación y la 
transcendencia. En el poema tan conocido y difundido "Aspaldian utzitako celda" [La celda que dejé hace tiempo] ${ }^{21}$, muestra las comunicaciones codificadas, las inscripciones murales y la dualidad entre individuo y colectividad.

Pero en lo que a la difusión y posición sistémica se refiere, adquiere unos rasgos distintivos. El poemario Gartzelako poemak (1992), reúne algunas características que no reunían los poemas carcelarios publicados o difundidos hasta entonces: es un poeta preso (V no un preso poeta) quien publica la obra; abre una tipología poética que tendrá seguida en la literatura vasca, al ser un poemario que trata exclusivamente de la experiencia carcelaria; y se publicó en la editorial Susa, que como he mencionado, es una de las editoriales más prestigiosas en lo que al género poético se refiere. Por otra parte, todas las personas presas que han publicado en editoriales literarias obras poéticas son miembros de un colectivo articulado bajo este nombre: Colectivo de Presos Políticos Vas $\cos ^{22}$. Son personas encarceladas por ser miembros de ETA, o por participar en movimientos políticos ilegalizados. En consiguiente, esa dualidad entre soledad y experiencia colectiva es más acentuada si cabe en estos poemarios: por ejemplo, se dedican poemas a compañeros y compañeras que han muerto en prisión ${ }^{23}$. Esa articulación colectiva en algunas ocasiones parece dificultar la creación de un sujeto poético individual (un yo poético), puesto que en la mayoría de los poemarios predomina un sujeto que representa a una colectividad (un nosotros poético). Únicamente al tratar la temática amorosa predomina esa posición individualizada, y un sujeto lírico que se ajusta a la poesía de corte romántico. Esa impronta romántica se aprecia tanto en los códigos amorosos como en el recurrente imaginario marino, que es consecuencia de la influencia de Sarrionandia. En su poética, el imaginario marino es una constante (Rodriguez 2014: 91-104), ecos de la navegación, de marineros errantes y de los naufragios, que nos evocan a la simbología romántica, pero que en el caso de Joseba Sarrionandia, en el poemario Gartzelako poemak, se vinculan estrechamente a la experiencia carcelaria: el preso, cual naufrago en el mar, navega a la deriva. La influencia de Sarrionandia es tal, que en todos los poemarios de Susa (excepto en el de Ekhiñe Eizagirre), se hace uso de esa metáfora y de esos símbolos ${ }^{24}$.

Por otro lado, los poemarios publicados en lengua vasca, se han escrito en cárceles del estado español o del estado francés. En ambos casos, aunque especialmente en las 
cárceles del estado español, los escritos en lengua vasca están especialmente censurados y vigilados (cuando no prohibidos). En ese contexto, la práctica de la escritura en euskera es un acto más de resistencia, es un territorio de libertad. Como el propio Joseba Sarrionandia (1992) escribe en el poema "Territorio librea" [Territorio libre], "euskara da gure territorio libre bakarra" [el euskera es nuestro único territorio libre].

\section{Alde erantzira nabil, de Ekhiñe Eizagirre}

Como he mencionado, hasta el 2016, año en el que Ekhiñe Eizagirre presentó Alde erantzira nabil, no se había publicado ningún poemario carcelario de autoría femenina, ni en la editorial Susa, ni en ninguna otra plataforma alternativa. ${ }^{25}$ En 2016, año en el que Ekhiñe Eizagirre publica el poemario, en el Colectivo de Presos Políticos Vascos había 51 presas (EMAGIN/EHBF 2017: 30). ${ }^{26}$ El 15\% de ese colectivo son mujeres, dato reseñable si se compara con otras realidades: en el Estado francés el 3\% de la población recluso es mujer, y en el Estado español el 7\% (EMAGIN/EHBF 2017: 30).

Considero que son varias las circunstancias que han demorado la escenificación público-literaria de voces de mujeres encarceladas. Por una parte, el imaginario genérico vinculado a la organización armada ha facilitado la escenificación pública de sujetos corporales masculinos (y de voces que representan esa posición masculina). En la década de los 80, un grupo de investigación coordinado por la antropóloga feminista Teresa del Valle analizó los imaginarios genéricos de la cultura vasca, y en esa aproximación también analizaron la imagen genérica que transmitía ETA. Un análisis que tres décadas más tarde está en plena vigencia, o así ha sido por lo menos hasta el alto el fuego de ETA. Me remito al análisis de dichas antropólogas feministas, porque disciernen claramente entre imaginario y realidad, que considero es primordial:

El espacio de ETA es [era] un espacio masculino. La imagen proyectada de ETA en escritos, carteles, pintadas y pegatinas es [era] una imagen de fuerza, de resistencia, simbolizada siempre por un elemento masculino: un puño de hombre, un brazo masculino sosteniendo en alto una metralleta. Aunque haya [hubo] algunas mujeres actuando en ETA, la presencia de la mujer no se refleja [reflejaba] a ningún nivel; se sabe [sabía] que existe [existía], que está [estaba], cuando se la detiene [detenía]. La idea de resistencia, de héroe que es capaz de dar su vida, no parece compatible con la idea de mujer. Esta separación de espacios es más patente en campañas a favor de los presos o 
exiliados [...]. Nada hace suponer o pensar en la existencia de mujeres entre los presos; rara vez aparecen 'presas' en algún comunicado o la imagen de una mujer en algún mural o cárcel. Hay presas de ETA en las cárceles; sin embargo en la mentalidad popular, sobre las presas políticas se ci erne un silencio absoluto. Las cárceles no son su espacio.

Por el contrario, y aquí la dicotomía dentro-fuera es perfecta, las mujeres están archipresentes entre quienes organizan las campañas pro-presos; la imagen de los familiares de presos, es una imagen de mujeres, son las madres, aunque también y cada vez más, las novias de ETA (Del Valle 1985: 243-244).

En reflexiones más actuales sobre el tema, se reitera esa predominancia del imaginario masculino: "De hecho, en el imaginario colectivo, se imponen el relato y la experiencia vital de los presos masculinos, y las vivencias de las mujeres presas permanecen más ocultas" (Martínez Pérez 2016: 54). 27 Ese imaginario masculino ha dificultado la escenificación de voces de mujeres encarceladas, no tanto por órdenes expresas, sino porque la representación colectiva se vinculaba simbólicamente a la figura del gudari, del guerrero, figura predominantemente masculinizada, y ese contexto no favorecía la toma de posición de diferentes sujetos genéricos: bien por no identificarse con tal imaginario, o bien por considerar que la posición representativa y pública debía encarnarla un cuerpo y voz que se aproximara al imaginario modélico. Asimismo, el Colectivo de Presos Políticos Vascos se ha pronunciado públicamente siempre mediante portavoces. En ese sentido, tanto el imaginario como la representatividad se han erigido en condiciones determinantes a la hora de pronunciarse públicamente. Evidentemente, el imaginario genérico (que no realidad) se ha descentrado con la disolución de ETA. Cabe destacar que fue una voz femenina quien anunció el alto el fuego definitivo en 2010, y que el Colectivo de Presos Políticos Vascos decidió en 2013 facilitar un proceso de excarcelación escalonado e individual (que en cierta medida, atenuaba la presión de la representatividad). Pero sobre todo, ese imaginario masculino y patriarcal se ha revisado gracias a las dinámicas feministas que se han generado (véase apartado 2).

Teniendo en cuenta las especificidades de la poesía carcelaria en lengua vasca (véase apartado 4), a continuación expondré cómo se ha renovado ese imaginario en Alde erantzira nabil. Los poemarios sobre la cárcel constituyen muchas veces un universo complejo e incluso contradictorio, en el interior del cual se entrecruzan memoria e imaginación, y donde 
el discurso asume varias formas y tonos: de crítica y denuncia, de resistencia y de reflexión, de autoconmiseración y de acusación, de testimonio y de ironía, de sarcasmo y de resignación. Es ésa una la característica discursiva de todos los poemarios carcelarios en lengua vasca, también el de Eizagirre (2016). La poesía actúa como una herramienta de resistencia en donde plasman su afán de libertad, reconstruyendo el mundo externo que representa una fuente de deseo inagotable. Cualquier fisura en los muros y ventanas activa la imaginación. Cada elemento, visible o no, adopta una dimensión proporcional al persistente anhelo que genera la simple posibilidad de estar fuera de la cárcel: los otoños, el vuelo de los pájaros, el viento, las nubes... mediante esa evocación constante se expresa el deseo de encarnarse en esos elementos que vienen a materializar la libertad ansiada. En ese sentido, esos elementos tan cotidianos para las personas no encarceladas, en estos poemas adquieren un significado bien distinto. Concretamente esta huida mediante los elementos de la naturaleza también se aprecia en el imaginario poético de Ekhiñe Eizagirre.

No obstante, al evocar a amantes, amistades y familiares, la propuesta poética de Ekhiñe Eizagirre difiere del resto. En los poemarios de autoría masculina, se hace referencia de esta manera al entorno afectivo: dedican poemas a sus amadas, recordando partes de sus cuerpos (sobre todo ojos, manos, pechos) (cuerpos troceados); expresan el deseo de habitar en los ojos de sus amadas o madres, e incluso, la certeza de habitar en los ojos de esas amadas y madres. ${ }^{28}$ Se presentan como sujetos dignos de ser cuidados, y representan a las mujeres tal cual penélopes que esperan a su guerrero. El amor romántico como fuerza y estrategia redentora. No se presentan como sujetos activos en el entorno afectivo, ni como partícipes de una red de cuidados. No hay en los poemarios de autoría masculina referencia alguna a la amistad, salvo al nombrar a compañeros presos: en un marcado discurso de alabanza a la fraternidad militante.

En el poemario de Ekhiñe Eizagirre, por el contrario, el entorno afectivo se articula de una manera bien diferente: por un lado, se representa a sí misma como sujeto activo en el cuidado, que no solamente es cuidada (por amigas, amantes y familiares), sino que también cuida de su entorno, con sus límites, evidentemente. En el poema "Ukan nazazu" [Cógeme] se aprecian todas esas temáticas: 
UKAN NAZAZU / Ukan nazazu / behar bai baina ez nagoenetan. / Bete ezin izan ditugun / gure bizitzako etenpuntuetan, / denboraren minutu luzeek /puzten duten parentesian / uki nazazu, / ukan nazazu. / Putzu gabeko oasi handi honetan / bila nazazu / eta ikusiko nauzu zelai idorrenak ere /ase ditzaketen oroitzapen goxoetan. / Ukan nazazu / behar bai baina ez nagoenetan. / Maitasunaren hariari jarraituz / aurkituko nauzu / etenpuntuak lerro zuzen bilakatzen dituzten /bihotz ttakun azkarretan. / Ukan nazazu / atzo, gaur eta biharko gauetan. /Bila nazazu hegan, / gaua argi tzen duten eta /hainbeste maite ditugun ilargi beteetan, / distantzia sekulakoek ninirik nini /ahitzen dituzten izar iheskorretan. / Ez nagoenetan, behar nauzunetan, / hitz sorgindu hauen bidez / senti nazazu gertu. / Heldu gogoz gerritik / eta eramango zaitut erratz gainean / denbora eta urruntasuna /laburtzen diren unibertsora, /absentziak sutan errez /ametsak egia bihurtzen diren akelarrera. / Ukan, usain, Iaztan nazazu. / Senti nazazu, eta elkartuko gara / irri, xirri eta muxuen lurralde askean" [CÓGEME / Cógeme / Cuando me necesites y no esté. / En los puntos suspensivos / de nuestra vida que no pudimos completar / en las paréntesis de los largos minutos / tócame, / cógeme. / En este Oasis sin pozo / búscame / y me verás en los recuerdos / que sacian incluso los prados más áridos. / Cógeme / cuando me necesites y no esté. / Me encontrarás / siguiendo el hilo del amor / en las rápidas palpitaciones / que hacen de los puntos suspensivos líneas directas. / Cógeme / en la noche de ayer, hoy y mañana. / Búscame al vuelo / en las lunas llenas / que alumbras las noches, y / tanto queremos, / en las estrellas huidizas / que consumen la distancia de pupila a pupila. / Cuando no esté, cuando me necesites, / siénteme cerca en / estas embrujadas palabras. / Cógeme con fuerza de la cintura / y te llevaré en mi escoba / al universo donde se acortan / el tiempo y la lejanía / quemando las ausencias / en el aquelarre que convierte los sueños en realidad. / Cógeme, huéleme, acaríciame, / Siénteme, y nos juntaremos en el libre / territorio de sonrisas, mimos y besos] (Eizagirre 2016: 36-37). [Traducción de la autora]

Por otro lado, hace una crítica a la institución familiar y a la monogamia. En los poemarios de autoría masculina, la monogamia es una constante encarnada en la figura de Penélope, que es a quien pertenece el corazón del poeta. Ekhiñe Eizagirre (2016: 41) expresa lo siguiente: "Bihotza / lur eremu zabalegia / jabe bakar bat izateko" [El corazón / un territorio demasiado extenso / para tener un únicx propietarix $].{ }^{29}$ En ese sentido, los poemas que tratan sobre la afectividad distan mucho de una visión romántica e idealizada del amor, e incluso lo cuestionan expresamente.

En esa revisión feminista también encarna un discurso homoerótico, festejando el placer lés bico, pero también la masturbación, el autoplacer, el autodescubrimiento. Visibiliza las relaciones lésbicas, tanto fuera como dentro de la cárcel. De esa manera, visibiliza el 
Poesía carcelaria, repertorio poético y subjetividades en conflicto: el poemario Alde erantzira nabil de Ekhiñe

lesbianismo dentro del sistema carcelario, pero también visibiliza el lesbianismo dentro del Colectivo de Presos Políticos Vascos. En ese colectivo, la homosexualidad ha sido una realidad que se ha invisibilizado (aunque en los últimos años expresos y expresas hayan hablado sobre sus experiencias en foros feministas).

En este caso concreto, por tanto, se repite la constante mencionada, en la que las mujeres presas recrean un sujeto corporeizado (Gelfand 1983: 21). Este sujeto corporeizado desea y goza, se proclama a sí mismo como sujeto sexuado y sexualizado, reivindicando esa posición política y erótica que la prisión le niega. En los poemarios de autoría masculina no se presenta placer alguno en el encarcelamiento, es por ello, que esa posición es subversiva: el placer, el goce y la sexualidad son un espacio de resistencia para hacer frente a la opresión y la muerte en vida que representa la prisión. Como ejemplo, el poema "Goiz gorri, arrats euri":

GOIZ GORRI, ARRATS EURI / hire ezpainen samurra / zetorkidan akordura / eguna esnatzear den / goiz gorri honetan / inkontzienteak kosk egin zidan / ezpainetako haragian / ebaki lizun hori ageri zainan / zoko horretan bertan" [AMANECER ROSADO, ATARDECER LLUVIOSO / Recuerdo / tus labios tiernos ${ }^{30}$ / en este amanecer rosado / cuando el día está por despertar / el inconsciente me mordió / en la carne de los labios / en ese mismo rincón / habita ese lujurioso corte] (Eizagirren 2016: 90). [Traducción de la autora]

Ese posicionamiento feminista, lleva a la poeta a integrar en los poemas referencias y discursos feministas: reivindica su agencia, al afirmar que va a hacer de la celda su habitación propia (en clara alusión a Virginia Woolf) ${ }^{31}$; retoma la genealogía de las sorgiñas o brujas y del aquelarre (expresa su conexión con esas brujas que quemaron y persiguieron) ${ }^{32}$; se identifica sobre todo con el colectivo feminista ( $y$ en segundo lugar, con el colectivo de presos), e incluso dedica un poema al feminismo, esa gran compañera:

FEMINISMOARI / zu zaitut / lau hormaren artean morfina / arintzen didana egonezina / jakin -min atsegina / itxaropen vitamina / egin dezadan aitzina / zu zaitut / bozkario eta samina / bizitzako pipermina / lagun ukaezina / adiskide nekaezina / maitale aseezina / zu zaitut / kontraesanak xuxurlatzen / dizkidan sorgina [AL FEMINISMO / Tú eres / entre estas cuatro paredes mi morfina / curiosidad apacible / vitamina de la esperanza / para que avance / Tú eres / alegría y dolor / la 
guindilla de la vida / amiga innegable / compañera incansable / amante insaciable / Tú eres / la bruja que me susurra / mis contradicciones (Eizagirren 2016: 68). [Traducción de la autora]

Cabe destacar esa construcción de una genealogía feminista, porque en los poemarios de autoría masculina se construye básicamente una genealogía de la resistencia nacional (son constantes las alusiones al pueblo, a la guerra y a la fraternidad militante). También escribe un poema desde la voz de una esposa maltratada, que se defiende de la violencia machista. De esa manera, sugiere una relación entre esposa maltratada y violencia carcelaria. Cesar Manzanos ha reflexionado así sobre la relación entre violencia machista y sistema penitenciario:

\footnotetext{
En este contexto, lo que resulta más grave en relación con la violencia que se ejerce en nuestra sociedad y con la complicidad de sus instituciones es que de un modo paradógico y per verso estamos poniendo en manos del sistema penal, del estado penal, la lucha contra la violencia hacia las mujeres, en manos de una institución que viola los derechos de las mujeres presas y que no establece dispositivos para combatirla. (Manzanos 2016: 50)
}

Por otra parte, se autodefine como puta, y no crea una brecha entre las diferentes reclusas, e invita a sus amistades a viajar al infierno, es pacio propicio para la transgresión. En ese sentido, a diferencia de los poemarios de autoría masculina, no describe la prisión como un infierno, sino que el infierno simboliza la rebeldía, la brujería y el aquelarre, la desobediencia, la libertad, etcétera.

En los poemarios de autoría masculina el sujeto encarcelado se representa como un sujeto helado, detenido en el tiempo, como un muerto en vida ( $\mathrm{y}$ la celda como una sepultura). Ekhiñe Eizagirre aboga por un sujeto nómada, en continua construcción, en movimiento: en un poema que reivindica la reconquista del cuerpo, expresa lo siguiente: “Horregatik gorputz ahaldunak. / Horregatik kontzientzia arriskutsuak. / Horregatik gure gorputzen birkonkistan / dihardugun nomada feministak" [Cuerpos empoderados / consciencias peligrosas / somos nómadas feministas que luchamos / por la reconquista de nuestros cuerpos] (Eizagirre 2016: 46). Así dictan otros versos: “Normala norma bada / hobe izan nomada" [Si lo normal es norma / mejor ser nómada] (Eizagirre 2016: 56). Una 
subjetividad nómada feminista, que se vincula a la conciencia nómade de Rosi Braidotti (2004):

La conciencia nómade es una forma de resistencia política a toda visión hegemónica y excluyente de la subjetividad [...]: una forma de resistirse a la asimilación y la homologación con las maneras dominantes de representación del yo. Las feministas - u otros intelectuales críticos que adoptan la posición de sujetos nómades-son aquellos que poseen una conciencia periférica; no se permiten olvidar la injusticia y la pobreza simbólica, pues su memoria se activa contra la corriente; representan la rebelión de los saberes sojuzgados. (Braidotti 2004: 216)

Esa reivindicación del sujeto nómada sugiere que la poeta considera que la cárcel también es un espacio de autoconocimiento, de socialización, de construcción de identidad, de transición y movilidad. Si observamos las portadas de los poemarios publicados en la editorial Susa, se aprecia claramente la diferencia.
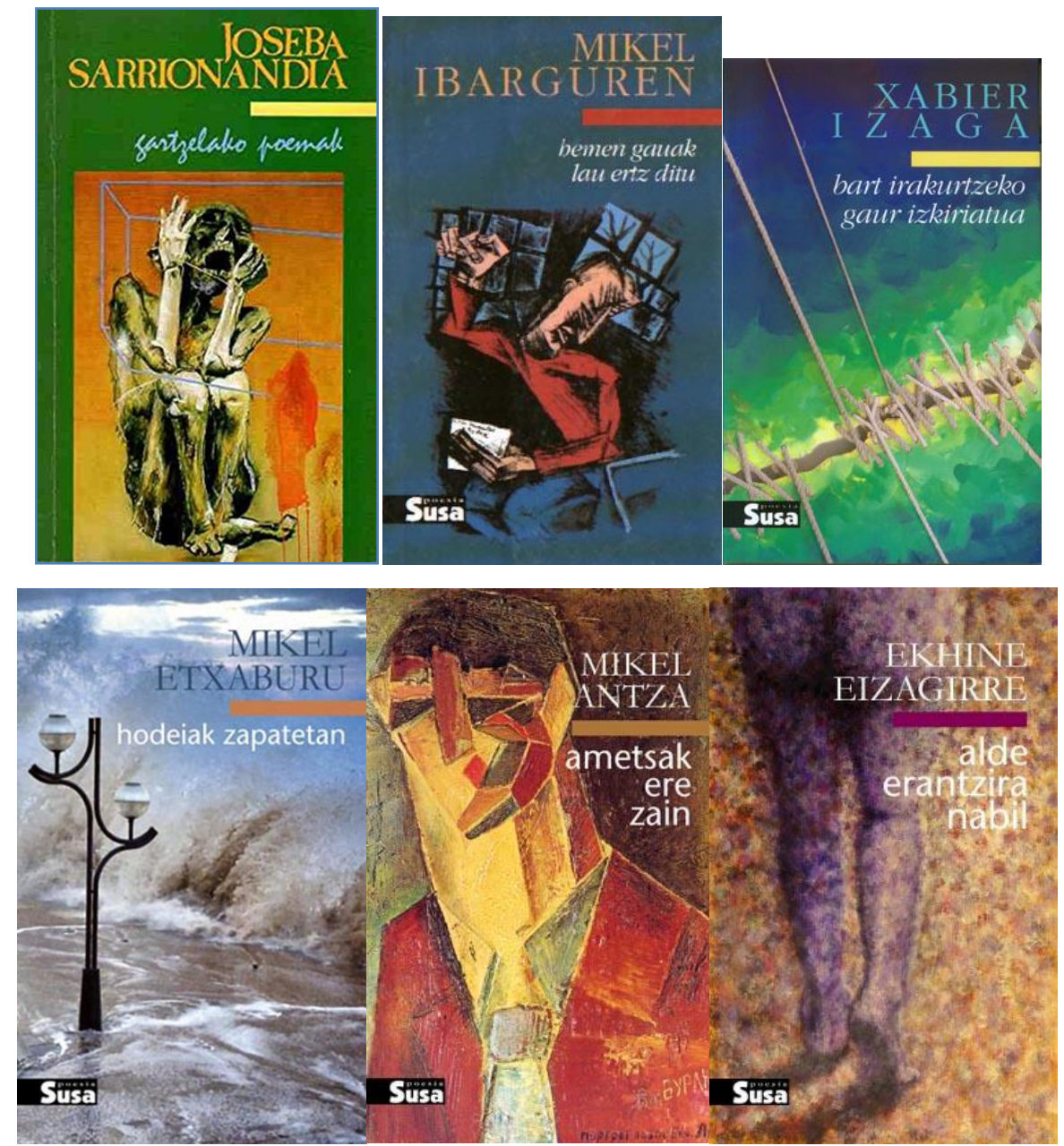
Como apunta Eider Rodriguez (2014: 91-92), la porta de Gartzelako poemak nos evoca al expresionista "Grito" de Munch, simbolizando la angustia y la deses peración. Tras la figura humana, se aprecia una geometría cúbica, que podemos vincular al espacio rígido carcelario (Rodriguez 2014: 92). En las siguientes portadas se representan o figuras corporales rotas y estáticos, o no hay cuerpo alguno representado, y simbólicamente se representa la sujeción o la tormenta. En Alde erantzira nabil, por el contrario, se representa un cuerpo en movimiento, un paso ligero y difuso, sin contornos tan rígidos y más fundido con el entorno.

En estos poemarios de autoría masculina son abundantes las reflexiones sobre la escritura, la palabra y la poesía, en un continuo gesto de autoafirmación poética. En todos los poemarios se han generado actos performativos que autodefinen los textos y discursos como poemas, e incluso se citan a poetas. En el poemario Alde erantzira nabil no se hace mención alguna a lo poético, ni a la escritura, ni a poeta alguno. Esta posición también se aprecia en los paratextos: en la mayoría de los poemarios publicados por la editorial Susa, se han añadido prólogos escritos por poetas, contextualizando los poemarios en la tradición literaria vasca. De hecho, la mayoría de los poemarios de autoría masculina se han difundido básicamente en circuitos literarios (ferias, recitales poéticos, encuentros literarios, etcétera). En el poemario de Ekhiñe Eizagirre no hay prólogo ni paratexto alguno, y fueron activistas feministas conocidas (e íntimas amigas de la poeta), quienes presentaron el poemario, y principalmente se difundió en recitales de círculos feministas.

\section{Breves conclusiones}

En conclusión, la propuesta poética de Ekhiñe Eizagirre ha renovado ese imaginario carcelario desde una perspectiva feminista, $y$ ha propuesto una nueva subjetividad carcelaria, e incluso, ha generado nuevas lógicas literario-políticas. Para que la incidencia política de la poesía sea efectiva, es necesario generar una red cultural y social que constituya esa práctica poética en acto performativo. En ese sentido, el poemario Alde erantzira nabil se ha inscrito en otro circuito: el movimiento feminista. La red de apoyo de Ekhiñe Eizagirre se ha organizado para que esta obra poética tenga incidencia en el ámbito político-ideológico del que ha emergido, y al que interpela. De esa manera, esta obra no 
únicamente ha renovado el imaginario poético carcelario en lengua vasca, sino también los mecanismos de incidencia poético-política. Al haber incidido en el movimiento feminista y en debates y actos feministas, el sujeto carcelario ha logrado transcender el sujeto colectivo al que está adscrito (Colectivo de Presos Políticos Vascos), posicionándose en relación a otro sujeto colectivo (el movimiento feminista), gracias al que puede repensarse y redefinirse, más allá de su condición de reclusa.

\section{NOTAS}

\footnotetext{
1 Este trabajo se enmarca tanto en el proyecto de investigación "Poesía actual y política: Análisis de las relaciones contemporáneas entre producción cultural y contexto sociopolítico" (POEPOLIT), financiado por el Ministerio de Economía y Competitividad del Gobierno de España (FFI2016-77584-P, 2016-2019), y dirigido por Burghard Baltrusch, como en proyecto de investigación "Análisis de género de las representaciones de los
} conflictos en la literatura vasca", financiado por la UPV/EHU (EHUA 16/26), y dirigido por Ibon Egaña.

2 El título del poemario no se puede traducir fielmente, porque en euskera tiene este triple significado: por un lado, "Camino del revés"; por otro lado, "Camino al desnudo" e incluso, "Camino por el lado desnudo"; y por último, "Camino hacia atrás". Por consiguiente, el título original aúna todas esas connotaciones que no se han podido expresar en la traducción.

${ }^{3}$ ETA entregó las armas el 8 de abril de 2017, y anunció su disolución el 4 de mayo de 2018.

${ }^{4}$ En 2012 Euskal Herriko Bilgune Feminista y Herrira organizaron varias mesas redondas para tratar el tema de "La mujer y la cárcel". Esas mesas redondas se organizaron en diferentes localidades del País Vasco (EMAGIN/EHBF 2017: 11). En julio de 2015, militantes y simpatizantes del movimiento feministaindependentista, Euskal Herriko Bilgune Feminista, organizó un curso de verano en la Udako Euskal Unibertsitatea [Universidad Vasca de Verano], para compartir experiencias y crear un foro de discusión: Euskal Herriko gatazkaren irakurketa etorkizuneko bake feministaren bidean [Lecturas sobre el conflicto vasco, en el 
camino hacia una paz feminista]. Tras ese foro, la asociación Emagin organizó en 2016 Pamplona y Bilbao una Escuela Feminista, para compartir experiencias e interpretaciones en el contexto del conflicto vasco. En 2017 Euskal Herriko Bilgune Feminista organizó una marcha de mujeres a la cárcel de Valladolid, para denunciar las discriminaciones a las que se somete a las presas.

${ }^{5}$ Véase www.ehu.eus/es/web/ehugune/emagune.

${ }^{6}$ Es significativo que Ekhiñe Eizagirre realizara las ilustraciones para el diseño del informe publicado por Euskal Herriko Bilgune Feminista sobre la situación de las presas políticas vascas (EMAGIN/EHBF 2017), y algunas de esas ilustraciones se utilizaron para decorar estas jornadas feministas: Emakume Abertzaleen VII. Topaketa Feministak (Berriozar, 6 de mayo de 2017) [VII. Encuentros Feministas de Mujeres Abertzales].

7 En el Estado español se les aplica el grado de FIES-3 (Ficheros de Internos de Especial Seguimiento), y en el Estado francés se les aplica el grado DFS (Detenu particuliarement signale) (EMAGIN/EHBF 2017: 30).

8 La escritora Maria José de Queiroz en las últimas páginas de su ensayo A literatura encarcerada (1981: 149152) presenta unas notas sobre voces femeninas encarceladas, y presenta los testimonios de la boliviana Domitila Barrios de Chúngara y de la brasileña Flávia Schilling. Cabe recordar que liberaron en 1980 a Flávia Schilling, tras años de lucha por su liberación y por la amnistía. En 1978 Flávia Schilling publicó las cartas a su familia en el volumen Querida família (Editora Coojornal), y en 1980 escribió sobre su experiencia carcelaria en Querida Liberdade (Editora Global). Es posible que ese contexto sociopolítico y sociocultural avivara el interés de Maria José de Queiroz por el estudio de la literatura carcelaria.

${ }^{9}$ La mayoría de estudios sobre literatura carcelaria, parten de esa premisa, y analizan el corpus de temática carcelaria o de experiencias carcelarias generadas por autores literarios. Ejemplo de ello es la compilación Nueve poetas encarcelados (Mandala Ediciones, 2011) de Áurea Galán de Silva.

${ }^{10}$ Anteriormente el poeta Joseba Sarrionandia publicó un poemario carcelario: Intxaur azal baten barruan / Eguberri amarauna (1983), pero no se publicó en una editorial literaria, sino que lo publicó el movimiento antirrepresivo Gestoras pro-amnistía (Rodríguez 2014: 63-72), y además, fue una colección anónima (no se responsabilizó públicamente de la autoría del poemario).

${ }^{11}$ Imanol Txabarri Hitzak naroa (Maiatz, 1985); Urtzi Zubizarreta, Kartzelako neurriak (Ataramiñe, 2008); Mikel Etxaburu, Zu zara orain txoria (Elkar, 2011); Ibon Muñoa, Ametsen txokoan bizi naiz (Ataramiñe, 2011); Oier Goitia, Fakin xokona (Ataramiñe, 2012); etcétera.

12 Jon Gaztelumendi, Haizea mindu gabe (Susa, 1999); Jokin Urain, Gatibu sortu nintzen (Susa, 2000); etcétera.

13 Jokin Urain, Izaina (Amnistiaren Aldeko Batzordeak, 1990); Jokin Urain, Adlotse (Txalaparta, 1992); Mikel Antza, Ospitalekoak (Susa, 2010); Carmen Gisasola, Gaur zortzi (Alberdania, 2012); etcétera.

14 Jokin Urain, Errotarria (Susa, 2006); Mikel Antza, Bakarmortuko kronikak (Ataramiñe, 2011); Markel Ormazabal, Hemen naiz, ez gelditzeko baina (Txalaparta, 2014); etcétera. 
Poesía carcelaria, repertorio poético y subjetividades en conflicto: el poemario Alde erantzira nabil de Ekhiñe

15 En el cómic destacan las tiras autoficcionales y humorísticas de Mikel Orbegozo: Preso nago y Preso nago 2 (Ataramiñe, 2013). Pero también se ha publicado algún otro álbum de cómic que retratan la experiencia carcelaria: Borxa Urberuaga, Espetxetik at (Ataramiñe, 2011).

16 De momento, se ha publicado una única obra teatral de temática carcelaria, escrita por un preso: Mikel Antza, Z ber bi (Ataramiñe, 2013).

17 Joseba Sarrionandia, Gartzelako poemak [Poemas carcelarios] (Susa, 1992); Mikel Ibarguren, Hemen gauak lau ertz ditu [Aquí la noche tiene cuatro esquinas] (Susa, 1996); Xabier Izaga, Bart irakurtzeko gaur idatziak [Escrito hoy para leer anoche] (Susa, 1998); Mikel Etxaburu, Hodeiak zapatetan [Nubes en los zapatos] (Susa, 2014); Mikel Antza, Ametsak ere zain [Los sueños también a la espera] (Susa, 2015); etcétera.

18 Jokin Urain, Ez dago etxean [No está en casa] (Susa, 2010).

19 “II. GALDERA / Presoa zelda bazterrean, / bakarrik mintzatzen bezala. / Baina ez, armiarma bati / galdetzen dio 'Noiz arte?'. / Armiarma, berehala, / zintzilikatu eta haria / luzatzen jeisten da. / Eta badirudi hari luze hori dela / armiarmaren erantzuna". [IIo PREGUNTA / En un rincón de la celda, / como si hablase a solas. / Pero conversa con una araña, / le pregunta, ¿hasta cuándo? / La araña, al instante, / se cuelga y desciende / alargando el hilo. / Ese largo hilo semeja ser / la respuesta de la araña] [Traducción de la autora].

20 "LAU BOST SEI HARRESI / Lau, bost, sei harresi gure inguruan / bihotz bat bestearen barruan bezala. / Euriak zorionari eragindako kantua / laku zaharren batean ito zen, / haizeak ez dakar ezer. Begiratu hegaztien / itzal atzeman ezinak lurrean. / Zer egin dezakegu? Paseatu, urrats / bakoitzean errauts apur bat utziz; / mundua ere geure antzera biratzen da / bere buruaren giltza aurkitu ezinik" [CUATRO CINCO SEIS MUROS / Cuatro, cinco seis muros entre nosotros / como un corazón en el interior de otro / El canto que hizo la lluvia a la felicidad / Se ahogó en un viejo lago, / el viento no trae nada. Observa las sombras / inaccesibles de las aves en la tierra. / ¿Qué podemos hacer? Pasear, dejando un poco / de polvo a cada paso; / El mundo también vira como nosotros, alrededor de sí mismo, sin poder encontrar su llave] [Traducción de la autora].

21 “Aspaldian utzitako zelda / Jakin nahi nuke nork betetzen duen orain / nik utzitako zelda. / Ea entel egatzen duen hormako izkribu tipia: /'Eroria burrukara'. / Ea alboko zeldatik inork hots egiten dion / komuneko plastikozko / tuberia soltatuaz / telefonoz bezala mintzatzeko. / Ea hango egunak eternal dirauen, gauak izotzezko, / egunsentiak esne garratza diren. / Ea errekuentoan mirilatik soegiten duen begiak / - surveillir et punir - / inor ikusten duen edo iadanik inor ez / - denak ala inor ez-. / jakin nahi nuke ihes egin genuenok / benetan ihes egin genuen / ala ihes egitearena bizitzen irauteko / atxakia hutsa izan zen" [La celda que abandoné hace tiempo / Quisiera saber quién ocupa ahora / la celda que abandoné. / Si comprende el pequeño escrito de la pared: / 'Caído en la lucha'. /

Si alguien de la celda próxima lellama, / soltando del bañola tubería de plástico / para hablar cual teléfono. / Si los días allí permanecen eternales, las noches de hielo, / si los amaneceres son leche ácida. / Si en el recuento el ojo observa por la mirilla / - surveillir et punir - / si ve a alguien o ya no hay nadie / - todos o ninguno-. / 
Quisiera saber si los que escapamos, / lo cons eguimos de verdad / o lo de escapar fue una simple excusa / para poder seguir viviendo]. [Traducción de la autora]

22 Hay presos condenados por ser miembros de ETA o pertenecer a algún movimiento político ilegalizado que o bien han dejado el Colectivo de Presos Políticos (por no estar de acuerdo con las líneas políticas del colectivo), o bien no se han incorporado nunca al col ectivo.

${ }^{23}$ Los testimonios sobre prisioneros muertos en la cárcel es constante en la literatura carcelaria (el mismo Oscar Wilde dedicó su poemario a la memoria de C.T.W., prisionero muerto). En este caso, la diferencia estriba en que esos muertos son compañeros y compañeras de un colectivo articulado, con el que se comparten postulados, vivencias y redes afectivas y políticas.

${ }^{24}$ He aquí un poema de Mikel Etxaburu (2014), como ejemplo: "BELDUR / Itsasoa bare dagoenean / edonork izan nahi du kapitain, / baina behin naufragatuz gero / beti izango da itsasoaren beldur. / Horregatik ez naiz kapitain, / bi bider naufragatu ez dezadan. / Horregatik ez daukat ontzirik, / bi bider ito ez nadin. / Horregatik ikaratzen naiz / ukabilak harrotzen dituen enbatarekin" [TEMOR / Cuando el mar está sosegado / cualquiera quiere ser capitán, / pero en cuanto se naufraga / siempre se tendrá miedo al mar. / Por eso no soy capitán, / para no naufragar dos veces. / Por eso no tengo embarcación, / para que no se hunda dos veces. / Por eso tengo pavor / ante la tempestad que sacude los puños]. [Traducción de la autora]

${ }^{25}$ Las presas políticas vascas han publicado algunos textos sueltos en las publicaciones colectivas de Ataramiñe, pero hasta 2012, año de la publicación de la novela Gaur zortzi [Hace una semana] de Carmen Gisasola, no se publicó en euskera un libro autónomo de autoría femenina. Por consiguiente, Carmen Gisasola fue la primera presa de ETA que ha desarrollado una vozliteraria de temática carcelaria en lengua vasca. Cabe mencionar que Carmen Gisasola fue expulsada de ETA y del Colectivo de Presos Políticos Vascos en 1998, por cuestionar la violencia de ETA, y acogerse a la vía de reinserción.

26 “Las primeras presas fueron las del Proceso de Burgos. Después, a partir de 1989, se triplicó el número de presas políticas vascas, y se produjeron dos cambios: por una parte, el cuantitativo; y, por otra, el cualitativo (las mujeres pasaron de ser las compañeras de los militantes de ETA, a ser miembros o colaboradoras de la organización armada" (Martínez Pérez 2016: 60).

27 Trabajos recientes han analizado ese imaginario masculino y patriarcal (Rodriguez / Etxebarrieta 2016; EMAGIN/EHBF 2017).

${ }^{28}$ He aquí como ejemplo, dos poemas. El primero, un poema muy conocido de Sarrionandia (1992), dedicado a su madre: "Oroitzen zaitudanean, ama,/ sukaldean egoten zara / mahaia bostentzat atondu, / aulkian eseri eta leihotik / kristala lausotzen duen / lurrina / ezabatu gabe neguari begira / eta ni - badakit- / zure begien hondoan nagoela" [Siempre que te recuerdo, mamá, / estás en la cocina. La mesa está puesta para cinco. / Sentada en la silla, miras por la ventana,/sin quitar el vaho que empaña el cristal./ Y yo -lo sé muy bien- habito en tus ojos.]. El segundo, un poema de Mikel Ibarguren (1996), dedicado a su amada: "Patioari buel tak eman 
Poesía carcelaria, repertorio poético y subjetividades en conflicto: el poemario Alde erantzira nabil de Ekhiñe

dizkiodan heinean / Zutaz oroitzen naiz / Ez dakit zergatik kontatzen dizudan / Ahanztura geltoki abandonatua da ez dago trenbiderik / Ezin hel naiteke zugana baina zutaz oroitzen naiz / Gauaren uremean oheratzen naizenean / Ez nau beldurtzen denbora azkengabeak galdera ainguratuek / Urratsez urrats nongura dabilen joalea nauzu / Patioaren ertz batetik beste ertz batera / Liburu bat zabaltzen dudanean zutaz oroitzen naiz / Sentitzen zaitudanero nola ezagut zaitzaket

Bitartekaritzarik gabe maite nahi zaitut/ Distantziak sortu lubaki honez gaindi bihotz hustuak jendezta ditzagun / Bihotza deserria da orain / Itsasoak ez dakarren uhin bakoitza zure oinatz galdu bat da / Minez oroitzen naiz eta zugana arribatu nahi dut" [Mientras doy vueltas al patio / te recuerdo / no sé por qué te lo cuento / el olvido es una estación abandonada sin vías / no puedo llegar a ti / pero me acuerdo de ti / cuando me acuesto en las aguas de la noche / no tengo miedo del tiempo sin final, de las preguntas ancladas / soy un caminante que anda donde quiere paso a paso / de un rincón del patio a otro / al abrir un libro te recuerdo / como puedo conocerte cada vez que te siento /quiero quererte sin intermediarios / más allá de esta trinchera creada por distancias / poblar corazones vacíos / el corazón ahora es un destierro / cada onda que no trae el mar es un rastro tuyo desvanecido / te recuerdo con dolor y quiero arribar en ti]. [Traducción de la autora]

${ }^{29}$ En euskera no hay género gramatical, y por lo tanto, en la traducción no se ha marcado el género.

${ }^{30}$ En euskera hay una forma de tuteo informal, que se utiliza entre amistades, o entre personas que tienen una relación cercana, de intimidad o de confianza. Ese tuteo informal o afectivo es una de las pocas marcas gramaticales donde sí hay diferencia genérica. En este poema, mediante ese tuteo afectivo se dirige a una mujer, y expresa un deseo lésbico.

31 "GELA BAT NORBERARENA / gorrotoa tatuatuta daramat begi ninietan / a hanzturan galduta da ude begirada samurrak / ito egiten nau errepresioaren reality show honek /aztoratu behatxulo eta klakaden neurrigabekeriak / triku itxurako katu amorratuak bezala / ezin diet beste era batera so egin uniformeei / gorrotoa ez da konpainia ona ezleku honetan / ahanztura ez da solaskide aproposa bahitegian / eraikiko dut gela propio bat zulo honen barruan / laztan nazazuen begiradez eta irribarreez / malkoz itsasoratuko dut gorrotoa eta / samurtasunari egingo diot txokoa / metro karratua / gutxienez" [UNA HABITACIÓN PROPIA / Tengo el odio tatuado en las pupilas / están perdidas en el olvido las miradas tiernas / Me ahoga este reality show de la represión / me turban la desmesura de las mirillas y las clacadas / como enfurecidos gatos que semejan ser erizos / no puedo mirar de otra manera a los uniformados / el odio no es buena compañera en este no-lugar / el olvido no es un buen interlocutor en prisión / construiré una habitación propia dentro de este agujero / para que me acariciéis con miradas y sonrisas / echaré en lágrimas el odio a la mar / haré un rincón a la ternura / un metro cuadrado / al menos] (Eizagirre 2016: 82). [Traducción de la autora]

32 Las alusiones continuas a las brujas, como sujetos rebeldes, se aproximan mucho a la lectura histórica que Silvia Federici (2010) desarrolla sobre la regulación de los cuerpos de las mujeres. La bruja como posición política, se encarna en una mujer que es dueña de su cuerpo. 


\section{Bibliografía}

Almeda, Elisabet (2002), Corregir y castigar. El ayer y hoy de las cárceles de las mujeres, Barcelona, Bellaterra.

Bosworth, Mary (1999), Engendering Resistance: Agency and Power in Women's Prisons, Ashgate, Aldershot.

Braidotti, Rosi (2004), Feminismo, diferencia sexual y subjetividad nómade, Barcelona, Gedisa.

Brombert, Victor (1976), La prison romantique. Essai sur l'imaginaire, París, José Corti.

Davies, loan (1990), Writers in Prison, Oxford, Basil Blackwell.

Davis, Angela (2016), “Eztabaida piztu zuen hitzartzea” [La conferencia que suscitó debate], in GITE-IPES, Kartzela kalera! Emakumeak eta kartzela [iLa cárcel a las calles! Mujeres y cárcel], Bilbao, GITE-IPES, 85-115.

Dañobeitia, Olatz (2018), "Reflexiones metodológicas sobre investigación en violencia", IV. Jornadas de Metodología de Investigación Feminista: violencias y resistencias, Hegoa (UPV/EHU)-SIMReF, Bilbao, 24-25 mayo de 2018.

Del Valle, Teresa (dir.) (1985), "Visión de la mujer en el nacionalismo vasco", in Teresa del Valle (dir.), Mujer vasca. Imagen y realidad, Barcelona, Anthropos, 226-256.

De Miguel Calvo, Estibaliz (2016), "Mujeres encarceladas. Una mirada feminista", in GITEIPES, Kartzela kalera! Emakumeak eta kartzela [iLa cárcel a las calles! Mujeres y cárcel], Bilbao, GITE-IPES, 16-33.

Doherty, Brian Francis (1996), Prison Writers / Escape Artists: Containment and Identity in Twentieth-Century Literature, Milwaukee, University of Wisconsin.

Eizagirre, Ekhiñe (2016), Alde erantzira nabil, Zarautz, Susa.

EMAGIN/Euskal Herriko Bilgune Feminista (2017), Hau ez da gure bakea. Euskal Herriko gatazka eta emakume preso politikoen inguruko irakurketa feministak [Esta no es nuestra paz. Conflicto vasco y lecturas feministas sobre las presas políticas], autoedición. 
Etxaburu, Mikel (2014), Zapatak hodeietan, Zarautz, Susa.

Federici, Silvia (2010), El caliban y la bruja. Mujeres, cuerpo y acumulación originaria, Madrid, Traficantes de Sueños [2004].

Foucault, Michel (2012), Vigilar y castigar: nacimiento de la prisión, Madrid, Biblioteca Nueva [1975].

Franklin, H. Bruce (1998), Prison Writing in 20th-century America, New York, Penguin.

Galán de Silva, Áurea (2011), Nueve poetas encarcelados, Madrid, Mandala Ediciones.

Gelfand, Elissa D. (1983), Imagination in Confinement: Women's Writings from French Prisons, Ithaca, NY: Cornell University Press.

Grau Biosca, Elena (2014), "Saber que alguien lo escucha. El método de la narrativa en la investigación. La verdad de las mujeres. Víctimas del conflicto armado en Colombia", in Irantzu Mendia / Marta Luxán / Matxalen Legarreta / Gloria Guzmán / Iker Zirion / Jokin Azpiazu (eds), Otras formas de (re)conocer. Reflexiones, herramientas y aplicaciones desde la investigación feminista, Bilbao, Hegoa (UPV/EHU)-SIMReF, 147-160

Guillard, Amandine (2015), “(Re)construcción del mundo exterior en la poesía carcelaria Argentina (1976-1983)", Astrolabio, o 15, 49-67.

Ibarguren, Mikel (1996), Hemen gauak lau ertz ditu, Zarautz, Susa.

Juliano, Dolores (2011), Presunción de inocencia. Riesgo, delito y pecado en femenino, Donostia-San Sebastián, Gakoa.

Harlow, Barbara (1987), Resistance Literature, New York, Methuen.

Harlow, Barbara (1992), Barred Women. Writing and Political Detention, Hanover, NH, Wesleyan University Press.

Hernández Holgado, Fernando (2011), La prisión militante: las cárceles franquistas de mujeres de Barcelona y Madrid (1939-1945), tesis doctoral, Madrid, Universidad Complutense de Madrid, Departamento de Historia Contemporánea. 
Lourido, Isaac (2012), "Escrever desde o cárcere: a poesia como fenda no Estado penal", in II Simposio CIPPCE: Cultura e Crise, Santiago de Compostela, Universidade de Santiago de Compostela, 25-26 de outubro de 2012.

Lourido, Isaac (2015), “Marginalidad social y antagonismo político en la poesía de Patricia Heras", in Alba Cid / Isaac Lourido, La poesía actual en el espacio público, Bélgica, Orbis Tertius, 219-236.

McCann, Fiona (2012), “'The Good Terrorist(s)'? Interrogating Gender and Violence in Ann Devlin's 'Naming the Names'and Anna Burns' No Bones”, Journal of Irish Studies, no 7, 69-78. McCann, Fiona (2015), “Commitment and Poetic Justice. Irish Republican Women's Prison Writing", Commonwealth Essays and Studies, № 38-1, otoño 2015, 57-66.

Manzanos, Cesar (2016), "Cárcel: violencia institucional contra las mujeres", in GITE-IPES, Kartzela kalera! Emakumeak eta kartzela [iLa cárcel a las calles! Mujeres y cárcel], Bilbao, GITE-IPES, 36-51-

Martínez Pérez, Leire (2016), "Visibilizando la situación de las presas políticas vascas", in GITE-IPES, Kartzela kalera! Emakumeak eta kartzela [iLa cárcel a las calles! Mujeres y cárcel], Bilbao, GITE-IPES, 54-65.

Matthews, Roger (2003), Pagando tiempo. Una introducción a la sociología del encarcelamiento, Barcelona, Bellaterra.

Poli Junior, Ovídio (2009), A pena e o cadafalso: observações sobre a literatura carcerária relativa ao período do Estado Novo, São Paolo, Universidade de São Paolo.

Queiroz, Maria José de (1981), A literatura encarcerada: ensaio, Rio de Janeiro, Civilização Brasileira.

Regan, J. Ward (ed.) (2015), Great Books Written in Prison. Essays on Classic Works from Plato to Martin Luther King, Jr., Jefferson-North Carolina, McFarland \& Company.

Retolaza, Iratxe (2014), “Kartzela-kronikak eta kartografiak. Subjektu kartzelatutik kartzelasubjektura", in Markel Ormazabal, Hemen naiz, ez gelditzeko baina [Estoy aqui, pero no para quedarme], Tafalla, Txalaparta, 2014, 141-162. 
Rodriguez, Eider (2014), Itsasoa da bide bakarra. Sarrionandia irakurriz [El mar es el único camino. Leyendo a Sarrionandia], Donostia-San Sebastián, Utriusque Vasconiae.

Rodriguez, Zuriñe / Oihana Etxebarrieta (2016), Borroka armatua eta kartzelak [Lucha armada y cárceles], Zarautz, Susa (Lisipe).

Ruiz Torrado, Maria (2017), Kartzela genero-erakunde bezala. Bereizkeriak, erresistentziak eta agentzia Euskal Herrian espetxeratutako emakumeen artean [La cárcel como institución de género. Discriminaciones, resistencias y agencias entre las mujeres encarceladas en el País Vasco], Bilbao, UEU.

Sainz de Rozas, Rafael (2016), "Situación de las cárceles de la Comunidad Autónoma Vasca y retos del futuro", in GITE-IPES, Kartzela kalera! Emakumeak eta kartzela [iLa cárcel a las calles! Mujeres y cárcel], Bilbao, GITE-IPES, 70-83.

Sarrionandia, Joseba (1992), Gartzelako poemak, Zarautz, Susa.

Sedlak, Wemer (1996), "Prison Memoirs by African Writers (Ngugi, Pheto, Soyinka): The Cultural Unity and Complexity of Resistance", in Peter O. Stummer \& Chrisopher Balme (eds.), Fusion of Cultures?, Amsterdam, Rodopi, 1996, 183-92. 
Iratxe Retolaza Gutierrez es profesora de la Facultad de Ciencias Sociales y de la Comunicación de la UPV-EHU. Sus investigaciones se enmarcan principalmente en estas dos vertientes: por un lado, se ha especializado en crítica literaria feminista, analizando principalmente aportaciones de la literatura vasca actual; y por otro lado, investiga tanto dimensiones performativas como dimensiones políticas de las prácticas poéticas. En el ámbito de la cultura vasca ha publicado estos dos libros de referencia en investigación feminista: junto a Isa Castillo ha coordinado Genero-ariketak. Feminismoaren subjektuak (Edo!, 2014) [Ejercicios de género. Sujetos del feminismo]; junto a Edurne Epelde y Miren Aranguren ha publicado Gure Genealogia Feministak (Emagin, 2015) [Nuestras Genealogías Feministas]. A su vez, ha colaborado en dos capítulos en el volumen $A$ New History of Iberian Feminisms (University of Toronto Press, 2018), coordinado por Silvia Bermúdez y Roberta Johnson. Es miembro de Emagin, Centro de Formación e Investigación Feminista. 